\title{
Kualitas Produk, Servicescape dan Word of Mouth Serta Pengaruhnya terhadap Keputusan Pembelian Ulang
}

\author{
Muhammad Zulkarnain \\ Sekolah Tinggi Ilmu Manajemen Pase \\ Jalan Kebun Baru No. 5A Langsa \\ m.zulkarnain28@gmail.com \\ Abdul Latief \\ Prodi Manajemen Fakultas Ekonomi Universitas Samudra \\ Jalan Prof Dr. Syarief Thayeb Meurandeh Langsa
}

\begin{abstract}
This writing was done in order to determine the effect of product quality, servicescape, word of mouth on repurchase decisions. This study uses primary data sourced from questionnaires and the sample used is 75 respondents who are consumers of the Warung Kop Rahmat. Methods of data analysis using multiple linear regression equations, coefficient of determination $\left(R^{2}\right), t$ test and $F$ test. The results showed that product quality, servicescape, word of mouth have a positive effect on repurchase decisions at Warung Kopi Rahmat . The coefficient of determination test results obtained $61.1 \%$ product quality, servicescape, word of mouth can explain the repurchase decision. While the t test results of product quality, servicescape partially have a significant effect on repurchase decisions and word of mouth has no significant effect on repurchase decisions. The results of the F test, product quality, servicescape, word of mouth simultaneously have a significant effect on repurchase decisions.
\end{abstract}

Keywords- Product Quality; Servicescape; Word of Mouth; Repurchase Decision

\begin{abstract}
Abstrak- Penulisan ini dilakukan dengan tujuan untuk mengetahui pengaruh kualitas produk, servicescape, word of mouth terhadap keputusan pembelian ulang. Penelitian ini menggunakan data primer yang bersumber dari kuesioner dan sampel yang digunakan sebanyak 75 responden yang merupakan konsumen dari Warung Kopi Rahmat. Metode analisis data menggunakan persamaan regersi linier berganda, uji koefisien determinasi $\left(\mathbf{R}^{2}\right)$, uji t dan uji F. Hasil penelitian diketahui bahwa kualitas produk, servicescape, word of mouth berpengaruh positif terhadap keputusan pembelian ulang pada Warung Kopi Rahmat. Hasil uji koefisien determinasi diperoleh 61,1\% kualitas produk, servicescape, word of mouth dapat menjelaskan keputusan pembelian ulang. Sementara hasil uji $t$ kualitas produk, servicescape secara parsial berpengaruh signifikan terhadap keputusan pembelian ulang dan word of mouth berpengaruh tidak signifikan terhadap keputusan pembelian ulang. Hasil uji F, kualitas produk, servicescape, word of mouth secara simultan berpengaruh signifikan terhadap keputusan pembelian ulang.
\end{abstract}

Kata Kunci- Kualitas Produk; Servicescape; Word of Mouth; Keputusan Pembelian Ulang

\section{PENDAHULUAN}

Aceh dikenal juga dengan sebutan seribu warung kopi. Hal tersebut karena kopi sejak dahulu sudah menjadi minuman bagi masyarakat Indonesia pada umumnya dan Aceh khususnya. Kopi menjadi lebih banyak konsumenya juga dikarenakan Aceh juga penghasil kopi. Perkembangan minuman kopi yang disediakan oleh penyedia berkembang sesuai dengan zaman. Perkembangan dapat dilihat dari penjual kopi tidak hanya terbatas pada warung kopi melainkan dari pinggir jalan, café sampai dengan restoran maupun hotel.

Kota Langsa sebagai salah satu daerah di Kota Langsa juga terdapat banyak warung kopi. Warung kopi yang sederhana (hanya sekedar warung kopi) dan juga yang modern (menyediakan layanan wifi, tempat yang tertata dengan layout yang dapat digunakan pengunjung sebagai tempat berswafoto). Banyaknya warung kopi yang menawarkan kelebihan-kelebihan dalam menarik konsumen menjadikan pemilik usaha harus dapat memberikan yang terbaik kepada konsumen. Hal tersebut juga akan memberikan dampak pada minat untuk melakukan pembelian ulang atau konsumen akan berkunjung ulang.

Keputusan pembelian ulang yang dilakukan konsumen pada sebuah warung kopi dapat dikarenakan kualitas produk kopi yang cocok atau sesuai dengan keinginan konsumen, kemudian dapat pula karena servicescape atau lingkungan layanan dan merupakan elemen dari bauran pemasaran jasa, serta dapat pula karena word of mouth mengenai warung kopi tersebut.

Kualitas produk pada warung kopi adalah kualitas dari produk-produk yang ada di warung kopi seperti minuman kopi yang selalu terjaga rasanya, makanan 
dan minuman lain dengan kualitas baik. Kemudian servicescape atau lingkungan layanan merupakan elemen bauran pemasaran jasa yang secara nyata turut mempengaruhi rasa puas konsumen terhadap suatu produk dan jasa yang diberikan. Servicescape pada warung kopi memiliki peranan sebagai kemasan dari jasa yang ditawarkan. Servicescape juga memfasilitas kegiatan individu dalam lingkungan jasa. Selain kualitas produk dan servicescape terdapat pula hal yang mempengaruhi konsumen untuk melakukan keputusan pembelian ulang produk berupa pengaruh orang lain yaitu word of mouth atau penyampaian informasi mengenai produk atau jasa kepada keluarga, teman, dan orang lain mengenai produk jasa yang telah digunakannya. Penyampaian informasi ini dapat negatif dan positif.

Salah satu warung kopi yang sudah berdiri sejak tahun 1985 hingga saat ini adalah warung kopi rahmat. Usaha ini telah membuka cabang tiga tempat selain di Kota Langsa yaitu di Aceh Tamiang. Warung kopi menarik diteliti karena telah mengikuti perkembangan warung kopi dimana semula hanya menyediakan kopi tetapi telah melakukan perubahan dengan penataan yang modern dan menyediakan berbagai menu makanan untuk melengkapi minuman kopi.

Berdasarkan penelitian sebelumnya bahwa kualitas produk, servicescape dan word of mouth memberikan pengaruh terhadap keputusan pembelian ulang maupun minat beli ulang, (Santosa, 2019) (Manambe, Hesty Fanny; Lapian, S.L.H.V Joyce; Soegoto, 2019), (Joesyiana, 2018), (Frista et al., n.d.) dan (Yunisya \& Yuliati, 2017)

survey awal yang dilakukan pada konsumen warung kopi Rahmat terdapat konsumen yang menyatakan kualitas produk yang baik dan terdapat pula yang kontra terhadap kualitas produk yaitu rasa kurang manis, munuman dingin yang esnya terlalu sedikit, ukuran minuman menjadi sedikit berkurang pada kunjungan setelah kunjungan pertama. Servicescafe berupa lingkungan layanan terdapat konsumen yang menyatakan tempat yang nyaman dan yang kontra menyatakan kurang nyaman dengan suara musik terlalu keras, serta signal wifi yang kurang baik saat digunakan untuk menghubungan gadget ke internet serta tempat yang terlalu dekat dengan jalan menyebabkan terdapat debu. Sementara konsumen yang menerima informasi dari orang lain (word of mouth) positif yaitu kualitas produk yang baik, tempat yang mudah dikunjungi dan juga nyaman.

Berdasarkan latar belakang maka penelitian ini dilakukan dengan judul "Kualitas Produk, Servicescape dan Word of Mouth serta Pengaruhnya terhadap Keputusan Pembelian Ulang". Penelitian dilakukan pada warung Kopi Rahmat di Kota Langsa - Aceh, dengan rumusan masalah apakah kualitas produk, servicescape dan word of mouth secara parsial dan simultan berpengaruh terhadap keputusan pembelian ulang. Sementara yang menjadi tujuan penelitian adalah untuk mengetahui kualitas produk, servicescape dan word of mouth secara parsial dan simultan berpengaruh terhadap keputusan pembelian ulang.

\section{KAJIAN PUSTAKA}

Keputusan pembelian ulang yaitu sebagai kondisi dimana konsumen memiliki perilaku yang positif terhadap suatu merek, dan memiliki komitmen pada merek tersebut serta bermaksud meneruskan pembeliannya dimasa yang akan datang. Indikator keputusan pembelian ulang, (Mowen, John C; Minor, 2012).

(Tjiptono, 2012) menyatakan terdapat tiga indikator untuk mengukur keputusan pembelian ulang, yaitu:

1. Melakukan pembelian ulang.

2. Merekomendasikan kepada orang lain

3. Tidak ingin pindah ke merek lain

(Saladin, 2011) mengungkapkan kualitas produk merupakan pemahaman bahwa produk yang ditawarkan oleh penjual mempunyai nilai jual lebih yang tidak dimiliki oleh pesaing, oleh karena itu perusahaan berusaha memfokuskan pada kualitas dan membandingkannya dengan produk yang ditawarkan oleh perusahaan pesaing.

(Kotler, Philip; Armstrong, 2012) berpendapat bahwa kualitas produk adalah karakteristik produk atau jasa yang tergantung pada kemampuannya untuk memuaskan kebutuhan pelanggan yang dinyatakan atau diimplikasikan.

dimensi kualitas produk ini menurut (Tjiptono, 2012) adalah sebagai berikut:

1. Kinerja (Performance), merupakan karakteristik operasi dasar dari suatu produk, misalnya kecepatan pengiriman paket titipan kilat, ketajaman gambar dan warna sebuah televisi, serta kebersihan masakan di restoran.

2. Fitur (features) yaitu karakteristik pelengkap khusus yang bisa menambah pengalaman pemakai produk, contohnya minuman gratis selama penerbangan pesawat, AC mobil, dan koleksi tambahan aneka nada panggil telepon genggam. 
3. Reliabilitas (reliability) yaitu probabilitas terjadinya kegagalan atau kerusakan produk dalam periode waktu tertentu. Semakin kecil kemungkinan terjadinya kerusakan semakin andal produk bersangkutan.

4. Konformasi (conformance) yaitu tingkat kesesuaian dengan standar yang telah ditetapkan, misalnya ketepatan waktu dari keberangkatan dan kedatangan kereta api, dan kesesuaian antara ukuran sepatu dengan standar yang berlaku.

5. Daya tahan (durability) yaitu jumlah pemakaian produk sebelum produk bersangkutan diganti. Semakin besar frekuensi pemakaian normal yang dimungkinkan, semakin besar pula daya tahan produk.

6. Dapat diperbaiki (serviceability) yaitu karakteristik kecepatan dan kemudahan untuk direparasi, serta kompetensi dan keramahtamahan staf layanan.

7. Estetika (aesthetics) merupakan penampilan produk yang bisa dinilai dengan panca indera (rasa, aroma, suara, dan lain-lainnya).

8. Persepsi terhadap kualitas (perceived quality) yaitu kualitas yang dinilai berdasarkan reputasi penjual.

(Render, 2014) mendefinisikan servicescape sebagai lingkungan fisik di masa jasa dilakukan dan bagaiman lingkungan ini memiliki dampak pada pelanggan dan karyawan. Pendapat lain menyatakan bahwa servicescape merupakan kesan yang tercipta pada indra yang dirancang dari lingkungan fisik pada jasa saat diserahkan, (Wirzt, 2011).

(Hasan, 2013) menyatakan bahwa word of mouth merupakan pernyataan tentang keunggulan jasa perusahaan yang disampaikan oleh orang lain yang terpercaya kepada nasabah. Selanjutnya (Rangkuty, 2009) mendefinisikan Word Of Mouth sebagai usaha pemasaran yang memicu pelanggan untuk membicarakan, mempromosikan, merekomendasikan dan menjual suatu produk, jasa atau merek kepada pelanggan lain.

(Rangkuty, 2009) menyatakan bahwa Word of Mouth dapat diukur dengan indikator-indikator yaitu dengan melihat hubungan antara lawan bicara anda mengenai produk dan tindakan anda setelah melakukan pembicaraan mengenai produk tersebut. Indikator meliputi:

1. Keahlian lawan bicara yaitu keahlian seseorang menyampaikan informasi produk.
2. Niat memberikan informasi yaitu keinginan untuk memberikan informasi atau mempromosikan produk.

3. Kepercayaan terhadap lawan bicara yaitu menerima informasi produk dari lawan bicara.

4. Daya tarik yaitu ketertarikan terhadap informasi yang diterima dari teman.

5. Kejujuran informasi yaitu kebenaran informasi yang diterima

\section{METODE PENELITIAN}

Metode penelitian yang digunakan adalah metode kuantitatif. Sementara yang digunakan adalah data primer yang bersumber dari kuesioner penelitian. Populasi dalam penelitian ini adalah konsumen dari warung kopi Rahmat yang jumlahnya tidak terbatas dan teknik sampling yang digunakan adalah sampling purposive dengan sampel yang digunakan sebanyak 75 orang yang diperoleh berdasarkan 25 kali jumlah variabel bebas yang diteliti (Ferdinand, 2014). metode, teknik pengumpulan data yang dilakukan melalui observasi, wawancara dan kuesioner, teknik analisis data yang digunakan adalah uji asumsi klasik, regresi linier berganda, uji koefisien determinasi $\left(\mathrm{R}^{2}\right)$ uji t dan uji F. Variabel penelitian terdiri dari variabel independen (kualitas produk, servicescape dan word of mouth dan variabel dependen berupa keputusan pembelian ulang. Keseluruhan variabel dengan pernyataan-pernyataan yang diajukan dinilai dengan skala likert 1-5.

Pengukuran variabel:

1. Keputusan pembelian ulang merupakan konsumen yang telah melakukan kunjungan ke Warung Kopi Rahmat dan ingin melakukan kunjungan kembali, yang diukur dengan indikator melakukan pembelian ulang, merekomendasikan pada orang lain dan tidak ingin pindah ke merek lain.

2. Kualitas produk adalah kebaikan atau karakteristik terutama mutu suatu produk yang disediakan Warung Kopi Rahmat seperti cita rasa, bahan baku, tingkat kebersihannya dan variasi bahan baku produk, yang diukur dengan indikator kinerja, fitur, keandalan, kesesuaian, estetika dan kesan kualitas.

3. Servicescape adalah segala sesuatu yang secara fisik hadir disekitar kosumen Warung Kopi Rahmat selama pertemuan transaksi layanan jasa yang dapat mempengaruhi persepsi pelanggan baik secara internal maupun eksternal, yang diukur dengan indikator kondisi lingkungan layanan (ambient conditions), tata ruang dan 
fungsi (spatial layout and functionality and signs) tanda, simbol dan artepak (symbol and artifacts).

4. Word of mouth adalah kegiatan pemasaran yang dilakukan dari sebuah merek yaitu Warung Kopi Rahmat melalui konsumen ke konsumen lainnya dengan cara memberikan informasi agar konsumen lain tertarik terhadap Warung Kopi Rahmat, yang diukur dengan indikator kehalian lawan bicara, niat memberikan informasi, kepercayaan terhadap lawan bicara dan daya tarik, kejuruan informasi.

\section{HASIL DAN PEMBAHASAN}

Berdasarkan hasil penelitian dengan menyebarkan kuesioner penelitian yang telah dilakukan pengujian validitas dan reliabilitas. Pada setiap variabel uji validitas diperoleh nilai sig $<5 \%$, dan uji reliabilitas dengan nilai cronbach alpha $>0,60$. Kemudian setelah dilakukan penelitian diketahui ratarata tanggapan pada setiap pernyataan yang diajukan.

Pengukuran kategori skor:

a. $<1,50$ sangat tidak setuju

b. $1,50-<2,50$ tidak setuju

c. 2,50 - $<3,50$ cukup setuju

d. $3,50-<4,50$ setuju

e. $>4,50$ sangat setuju

Tabel 1 Statistik deskriptif

\begin{tabular}{|l|c|c|c|}
\hline Variabel/Indikator & Pernyataan & Mean & Keterangan \\
\hline Keputusan pembelian & & & \\
ulang: & & & \\
1. melakukan & P1 & 4,1 & Setuju \\
pembelian ulang. & P2 & 4,0 & Setuju \\
2. Merekomendasikan & P3 & 3,9 & Setuju \\
pada orang lain. & P4 & 4,0 & Setuju \\
3. tidak ingin pindah ke & P5 & 3,9 & Setuju \\
merek lain & P6 & 3,7 & Setuju \\
\hline Kualitas Produk: & & & \\
1. Kinerja & P1 & 4,2 & Setuju \\
2. Fitur & P2 & 4,2 & Setuju \\
3. Keandalan & P3 & 4,0 & Setuju \\
4. Kesesuaian & P4 & 3,9 & Setuju \\
5. Estetika & P5 & 4,0 & Setuju \\
6. Kesan kualitas & P6 & 3,9 & Setuju \\
\hline Servicescape: & & & \\
1. Kondisi lingkungan & P1 & 4,0 & Setuju \\
layanan & P2 & 4,0 & Setuju \\
2. Tata ruang dan fungsi & P3 & 3,9 & Setuju \\
3. Tanda, simbol dan & P4 & 4,0 & Setuju \\
artepak & P5 & 3,9 & Setuju \\
& P6 & 3,8 & Setuju \\
\hline Word of mouth: & & & \\
1. Kehalian lawan & P1 & 4,2 & Setuju \\
bicara & P2 & 4,0 & Setuju \\
& P3 & 4,0 & Setuju \\
\hline
\end{tabular}

\begin{tabular}{|l|l|l|l|}
\hline 2. Niat memberikan & P4 & 3,9 & Setuju \\
informasi & P5 & 4,0 & Setuju \\
3. Kepercayaan & P6 & 4,0 & Setuju \\
terhadap lawan bicara & & & \\
dan daya tarik & & & \\
4. Kejuruan informasi & & & \\
\hline
\end{tabular}

Sumber: Data primer Penelitian, 2021

Berdasarkan table 1 dapat diketahui nilai mean atau rata dari setiap pernyataan antara 3,50 $-<4,50$ dapat dinyatakan bahwa setiap pernyataan yang diajukan pada keempat variable disetujui oleh responden.

Hasil uji asumsi klasik

Uji asumsi klasik dilakukan diantaranya:

1. uji normalitas

Uji normalitas dapat dilihat berdasarkan gambar berikut ini:

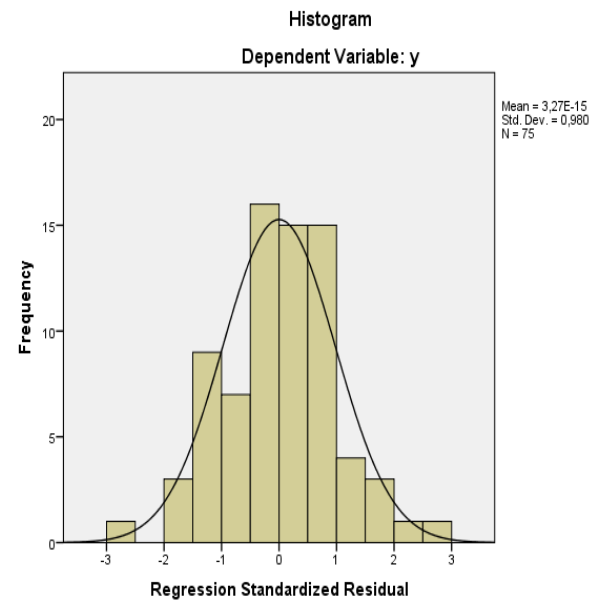

Sumber: Data primer penelitian, 2021 (diolah) Gambar 1: Histogram

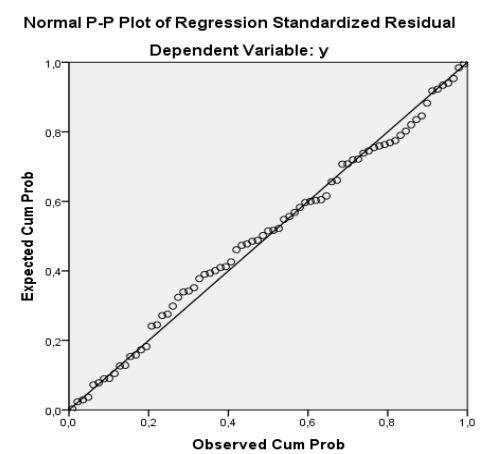

Sumber: Data primer penelitian, 2021 (diolah) Gambar 2: Normal P-P Plot 
Berdasarkan gambar 1 dan 2 uji normalitas diketahui bahwa data berdistribusi normal, dimana pada gambar 1 histogram membentuk lonceng dan pada gambar 2 titik-titik ploting berada pada sepanjang garis diagonal.

\section{Uji Heterokedastisitas}

Uji heterokedastisitas dilakukan dengan menggunakan gambar scatterplot.

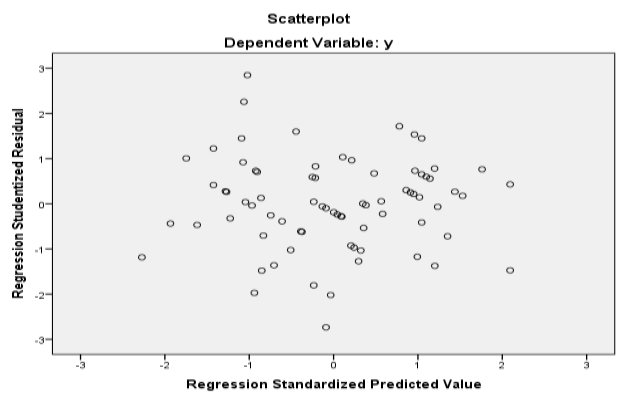

Sumber: Data primer penelitian, 2021 (diolah)

Gambar 3: Scatterplot

Berdasarkan gambar 3 diketahui bahwa titik-titik plot menyebar dan tidak membentuk pola tertentu atau titik-titik plot berada di atas dan di bawah titik 0 , sehingga dapat dinyatakan tidak terjadi heterokedastisitas.

3. Uji Multikolinearitas

Tabel 2: Uji Multikolinearitas

\begin{tabular}{|ll|r|r|}
\hline \multirow{2}{*}{ Model } & \multicolumn{2}{|c|}{ Collinearity Statistics } \\
\cline { 2 - 3 } & Tolerance & \multicolumn{1}{|c|}{ VIF } \\
\hline \multirow{2}{*}{1} & & \\
& Kualitas produk &, 583 & 1,716 \\
& Servicescape &, 457 & 2,187 \\
& Word of Mouth &, 631 & 1,586 \\
\hline
\end{tabular}

Sumber: Data primer penelitian, 2021 (diolah)

Berdasarkan hasil perhitungan pada tabel 2 diketahui bahwa nilai dari tolerance > 0,1 dan Variance Inflation Factor (VIF) $<10$, dapat dinyatakan pada semua variabel bebas tidak terjadi multikolinearitas.

\section{Persamaan Regresi Linier Berganda}

Hasil persamaan regresi linier berganda diketahui sebagai berikut:

Tabel 3: Regresi linier berganda, uji koefisien determinasi $\left(\mathrm{R}^{2}\right)$, uji $\mathrm{t}$ dan uji $\mathrm{F}$

\begin{tabular}{|l|c|c|c|}
\hline Uraian & B & t sig & Ket \\
\hline Constant & 0,821 & 0,042 & \\
\hline
\end{tabular}

\begin{tabular}{|l|l|l|c|}
\hline Kualitas produk & 0,178 & 0,043 & Signifikan \\
\hline Servicescape & 0,527 & 0,000 & Signifikan \\
\cline { 1 - 2 } Word of Mouth & 0,099 & 0,631 & Tidak signifikan \\
\hline $\mathrm{R}^{2}$ & 0,611 & \multicolumn{3}{|}{} \\
\cline { 1 - 2 } F sig & 0,000 & & \\
\hline
\end{tabular}

Sumber: Data primer penelitian, 2021 (diolah)

Hasil persamaan $\mathrm{Y}=0,821+0,178 \mathrm{X}_{1}+0,178 \mathrm{X}_{2}$ $+0,099 X_{3}$. Hasil persamaan menunjukkan keputusan pembelian ulang sebesar 0,821 pada saat kualitas produk, servicescape dan word of mouth dianggap nol. Koefisien regresi kualitas produk sebesar 0,178 menunjukkan bahwa kualitas produk berpengaruh positif dan searah terhadap keputusan pembelian ulang dan bila terjadi peningkatan kualitas produk meningkatkan keputusan pembelian ulang. Koefisien regersi servicescape sebesar 0,527 menunjukkan bahwa servicescape berpengaruh positif dan searah terhadap keputusan pembelian ulang dan bila terjadi peningkatan servicescape meningkatkan keputusan pembelian ulang. Koefisien regersi word of mouth sebesar 0,099 menunjukkan bahwa word of mouth berpengaruh positif dan searah terhadap keputusan pembelian ulang dan bila terjadi peningkatan word of mouth meningkatkan keputusan pembelian ulang.

Hasil uji statistik (uji t/uji parsial), kualitas produk diperoleh tsig sebesar $0,042<\alpha 5 \%$ menunjukkan bahwa kualitas produk berpengaruh signifikan terhadap keputusan pembelian ulang. Servicescape dipeolerh $\mathrm{t}$ sig sebesar $0,000<\alpha 5 \%$ menunjukkan bahwa servicescape berpengaruh positif signifikan terhadap keputusan pembelian ulang. Word of mouth diperoleh tsig sebesar 0,631 > $>5 \%$ menunjukkan bahwa word of mouth berpengaruh tidak signifikan terhadap keputusan pembelian ulang.

Hasil uji F diperoleh nilai F sig $<\alpha 5 \%(0,000<$ $0,05)$ dan dapat dinyatakan bahwa kualitas produk, servicescape dan word of mouth secara simultan berpengaruh signifikan terhadap keputusan pembelian ulang.

\section{Pengaruh Kualitas Produk terhadap Keputusan Pembelian Ulang}

Berdasarkan hasil penelitian diketahui bahwa kualitas produk berpengaruh positif dan signifikan terhadap keputusan pembelian ulang pada Warung Kopi Rahmat yang diketahui dari hasil persamaan regresi linier dengan koefisien 0,178 dan nilai signifikan 0,043. Hasil tersebut sejalan dengan 
wawancara singkat dengan responden penelitian saat menyebarkan kuesioner penelitian, dimana kualitas produk cukup baik dan sesuai keinginan dari konsumen sehingga menimbulkan rasa ingin kembali untuk melakukan pembelian ulang pada Warung Kopi Rahmat.

\section{Pengaruh Servicescape terhadap Keputusan Pembelian Ulang}

Berdasarkan hasil penelitian diketahui bahwa servicescape berpengaruh positif dan signifikan terhadap keputusan pembelian ulang pada Warung Kopi Rahmat yang diketahui dari hasil persamaan regresi linier dengan koefisien 0,527 dan nilai signifikan 0,000. Hasil tersebut sejalan dengan wawancara singkat dengan responden penelitian saat menyebarkan kuesioner penelitian, dimana kondisi lingkungan layanan yang selalu bersih, tata ruang yang menarik menurut konsumen dan juga benda-benda hiasan serta pelengkap tata ruang mendukung kenyamanan setiap konsumen yang dating berkunjung ke Warung Kopi Rahmat.

\section{Pengaruh Word of Mouth terhadap Keputusan Pembelian Ulang}

Berdasarkan hasil penelitian diketahui bahwa word of mouth berpengaruh positif dan tidak signifikan terhadap keputusan pembelian ulang pada Warung Kopi Rahmat yang diketahui dari hasil persamaan regresi linier dengan koefisien 0,099 dan nilai signifikan 0,631. Hasil tersebut positif karena dengan adanya word of mouth berupa informasi yang baik turut memberikan dampak terhadap keputusan pembelian ulang tetapi tidak signifikan karena word of mouth berupa informasi yang diterima konsumen dari lawan bicara sudah diketahui konsumen terlebih dahulu dan informasi tersebut diabaikan.

\section{KESIMPULAN DAN SARAN}

\section{A. Kesimpulan}

Berdasarkan hasil penelitian dapat disimpulkan bahwa kualitas produk, servicescape dan word of mouth berpengaruh positif dan signifikan terhadap keputusan pembelian ulang di Warung Kopi Rahmat. nilai koefisien determinasi sebesar $61,1 \%$ kualitas produk, servicescape dan word of mouth dapat menjelaskan keputusan pembelian ulang di Warung Kopi Rahmat.

B. Saran
Kepada pemilik usaha perlu melakukan perbaikan dibidang kualitas produk seperti menjaga rasa kopi yang tetap sama dan ukuran yang sama dengan membuat timbangan kopi dan air untuk setiap gelasnya sehingga hasilnya akan sama dan ukuran juga sama. Kemudian servicescape seperti suara musik yang terlalu keras dapat menyesuaikan suasana seperti pada siang hari memberikan musik dengan lantunan sendu serta untuk meja yang cepat berdebu selalu dibersihkan setiap saat.

\section{REFERENSI}

[1] Ferdinand, A. (2014). Metode Penelitian Manajemen, Pedoman Penelitian Untuk Penulisan Skripsi, Tesis dan Disertasi Ilmu Manajemen. Undip Press.

[2] Frista, R., Moningka, C., Loindong, S. S. R., Sam, U., \& Manado, R. (n.d.). Pengaruh servicescape dan lokasi terhadap keputusan pembelian pada manado town square i. 4(2), 778-788.

[3] Hasan, A. (2013). Marketing. Media Presindo.

[4] Joesyiana, K. (2018). Pengaruh Word Of Mouth Terhadap Keputusan Pembelian Konsumen pada Meida Onlineshop Shopee di Pekanbaru( Survey pada Mahasiswa Semester VII Jurusan Pendidikan Akuntansi Fakultas Keguruan dan Ilmu Pendidikan Universitas Islam Riau ). 4(1).

[5] Kotler, Philip; Armstrong, G. (2012). PrinsipPrinsip Pemasaran (13th ed.). Erlangga.

[6] Manambe, Hesty Fanny; Lapian, S.L.H.V Joyce; Soegoto, A. S. (2019). Keputusan Pembelian ( Studi pada Rumah Makan Rosita Mando) Product Quality,Price and Servicescape Influence on Purchasing Decisions ( Study at Rosita Manado Restaurant ). 7(4), 5456-5465.

[7] Mowen, John C; Minor, M. (2012). Perilaku Konsumen. Erlangga.

[8] Rangkuty, F. (2009). Strategi Promosi yang Kreatif dan Analisis Kasus Integrated Marketing Communication. Gramedia Pustaka Utama.

[9] Render, J. R. B. (2014). Manajemen Operasi. Salemba Empat.

[10] Saladin, D. (2011). Intisari Pemasaran dan Unsur-unsur Pemasaran. Kencana Prenada 
Media Group.

[11] Santosa, A. T. (2019). Pengaruh Kualitas Pelayanan, Kualias Produk, Store Atmosphere, dan E-WOM terhadap Proses Keputusan Pembelian ( Survei Terhadap Konsumen ZenbuHouse of Mozaru Paris Van. 18, 143-158.

[12] Tjiptono, F. (2012). Strategi Pemasaran. Andi.

[13] Wirzt, L. (2011). Pemasaran Jasa Perspektif
Edisi 7. Erlangga.

[14] Yunisya, N., \& Yuliati, A. L. (2017). ULANG ( Studi Pada Konsumen Giggle Box Café \& Resto Cihampelas Walk Bandung ). 11(2), 120-131. 